\section{(6) OPEN ACCESS}

\title{
Social disparities in heart disease risk and survivor bias among autoworkers: an examination based on survival models and g-estimation
}

\author{
Sadie Costello, ${ }^{1}$ Sally Picciotto, ${ }^{1}$ David H Rehkopf, ${ }^{2}$ Ellen A Eisen ${ }^{1}$
}

${ }^{1}$ School of Public Health, Environmental Health Sciences, University of California, Berkeley, California, USA ${ }^{2}$ Division of General Medical Disciplines, Stanford University School of Medicine, Stanford, California, USA

\section{Correspondence to} Dr Sadie Costello, School of Public Health, University of California, 50 University Hall, \#7360, Berkeley, CA 94720 7360, USA: sadie@berkeley.edu

Received 14 February 2014 Revised 21 August 2014 Accepted 14 October 2014 Published Online First 21 November 2014

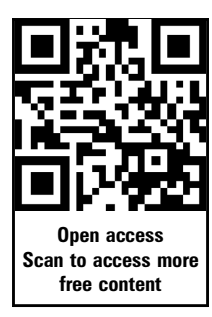

CrossMark

To cite: Costello $S$, Picciotto S, Rehkopf DH, et al. Occup Environ Med 2015;72:138-144.

\section{ABSTRACT}

Objectives To examine gender and racial disparities in ischaemic heart disease (IHD) mortality related to metalworking fluid exposures and in the healthy worker survivor effect.

Methods A cohort of white and black men and women autoworkers in the USA was followed from 1941 to 1995 with quantitative exposure to respirable particulate matter from water-based metalworking fluids. Separate analyses used proportional hazards models and g-estimation.

Results The HR for IHD among black men was 3.29 (95\% Cl 1.49 to 7.31 ) in the highest category of cumulative synthetic fluid exposure. The HR for IHD among white women exposed to soluble fluid reached 2.44 (95\% Cl 0.96 to 6.22). However, no increased risk was observed among white men until we corrected for the healthy worker survivor effect. Results from g-estimation indicate that if white male cases exposed to soluble or synthetic fluid had been unexposed to that fluid type, then 1.59 and 1.20 years of life would have been saved on average, respectively.

Conclusions We leveraged the strengths of two different analytic approaches to examine the IHD risks of metalworking fluids. All workers may have the same aetiological risk; however, black and female workers may experience more IHD from water-based metalworking fluid exposure because of a steeper exposure-response or weaker healthy worker survivor effect.

\section{INTRODUCTION}

Heart disease is the number one cause of death in the USA and also the main contributor to blackwhite disparities in mortality. ${ }^{1}$ Mortality rates from heart disease have declined in the USA overall since the 1970s, however there has been a steeper decline for whites compared to blacks, increasing the long-standing racial disparity. ${ }^{2}$ Although the two genders experience similar rates of heart disease incidence, women have higher mortality rates after heart attacks, for reasons not yet well understood. ${ }^{3}$

Exposure to particulate matter (PM) in ambient air pollution is now considered a risk factor for heart disease mortality. ${ }^{4}$ Occupational cohorts offer the opportunity to study long-term PM exposures that can occur at levels an order of magnitude higher than those found in the ambient setting. The sparse evidence that occupational PM exposure increases the risk of heart disease mortality

\section{What this paper adds}

- Occupational particulate matter $\left(\mathrm{PM}_{3.5}\right)$ and ischaemic heart disease (IHD) mortality have never before been reported by race and gender from a single cohort.

- Black men and white women had increased risk of IHD with increased exposure to at least one type of metalworking fluid.

- No increased risk was observed among white men until we corrected for the healthy worker survivor effect.

- There appear to be disparities in the healthy worker survivor effect and we cannot rule out disparities in heart disease from exposure to metalworking fluids.

derives mostly from studies of industrial cohorts of white men. ${ }^{5}$ Blacks and women may have greater exposure to occupational hazards in the USA, ${ }^{6}$ so an understanding of the impact of occupational exposures by race and gender may help lead to better protections.

The differential distribution of workplace factors by race and gender may create disparities in the healthy worker survivor bias, which can attenuate effect estimates in occupational studies. The bias arises if less healthy workers reduce exposure or self-select out of the work force earlier than their healthier counterparts. The healthy worker survivor effect has been studied mostly in the context of white, male cohorts; however, the likelihood of self-selection out of employment may well vary by race and gender. ${ }^{7}$

We assess disparities in ischaemic heart disease (IHD) and the healthy worker survivor effect using the United Autoworkers General Motors cohort-a large cohort of white and black men and women with individual-level, quantitative metalworking fluid exposure. Metalworking fluids are widely used in machining operations as coolants and lubricants during cutting or grinding operations. We report survival analyses of $\mathrm{PM}_{3.5}(\mathrm{PM}<3.5 \mu \mathrm{m}$ in diameter) generated by metalworking fluid on IHD mortality by race and gender. In addition to proportional hazards models, we use g-estimation of accelerated failure time models to adjust for the healthy worker survivor effect and compare the relative impact of the bias by race and gender. 


\section{METHODS}

\section{Study population}

The study includes 39412 hourly workers employed in one of three Michigan automobile manufacturing plants for at least 3 years and hired between 1 January 1938 and 31 December 1981. Follow-up began 3 years after hire and ended at the time of death or on December 31, $1994 .^{8}$ Vital status data were available starting on 1 January 1941. Information on age, gender, race and plant was obtained through records provided by the employer. Race was not recorded systematically prior to the implementation of electronic record keeping in the mid-1970s. Race information could be updated for workers who remained at work through the record keeping transition, but for others race remained unknown. ${ }^{9}$ The $10 \%$ of participants with unknown race were classified as white based on the racial composition of the time-specific and plant-specific workforce; however, we conducted sensitivity analyses in which unknown race was treated as a separate category.

\section{Exposure assessment}

Quantitative levels of exposure to each metalworking fluid class for plant, department and job were estimated over time, based on 541 personal and area samples for $\mathrm{PM}_{3.5}\left(\mathrm{mg} / \mathrm{m}^{3}\right)$ collected by industrial hygienists. ${ }^{10} 11$ On the basis of plant records, a type of fluid (straight, soluble or synthetic) was assigned to each plant-year, department-year, job-year and calendar-year specific exposure category. For jobs with mixed exposures, we estimated the percentage of time spent using each type of fluid. Scale factors were estimated to rank aerosol exposures relative to the baseline levels (1984). For example, for each unique combination of fluid type and operation, the scale factor was less than 1.0 by 1994, reflecting a continuing downward trend in exposure levels.

Annual average exposure to each type of fluid and size fraction was calculated for each participant by combining work histories with the estimated exposure concentrations. Cumulative exposure is the sum of annual exposures. Gaps in work history information for individual particpants were interpolated by averaging the exposures from the previous and subsequent jobs. Participants missing more than $50 \%$ of their work histories were excluded (less than 3\%).

\section{Health outcome}

Data on vital status and cause of death were obtained through the Social Security Administration, the National Death Index, plant records, death certificates and state mortality files. ${ }^{9}$ The outcome of interest for this analysis is mortality from IHD (ICD-9 410-414). Since only two black women in the cohort died of IHD, supplementary analyses were conducted with cardiopulmonary disease (ICD-9480-519) as the outcome in this stratum.

\section{Data analysis}

\section{Proportional hazards models}

Cox proportional hazard models were used to estimate the effect of cumulative exposure to soluble and synthetic fluids on IHD mortality separately by race and gender. Cumulative exposures to each fluid type were defined as categorical variables. Sensitivity analyses were conducted with duration of exposure to each fluid type as the main effect. Age was adjusted for as the time metric, calendar year (continuous) was included to adjust for secular trends, and manufacturing plant and other fluid types were included in every model. Supplementary models were fit with cumulative exposure modelled as penalised splines and further restricted to the plants in which there were exposed cases. The graphs were truncated at the 99th percentile of the exposure distribution. Degrees of freedom were based on minimum Akaike's Information Criterion and biological plausibility.

\section{G-estimation}

G-estimation of a structural accelerated failure time model, first described by Robins, ${ }^{12}$ quantifies the relationship between the counterfactual survival time if never exposed and certain observed quantities: the observed survival time and the observed exposure history. Adjustment for confounders is achieved by including covariates and prior exposure history in a model predicting exposure. Under the assumption of no unmeasured confounding, counterfactual outcomes are conditionally independent of observed exposures, within strata of the measured covariates. G-estimation refers to the use of optimisation procedures to achieve this statistical independence, and it represents one of several statistical g-methods for adjusting for timevarying confounders affected by prior exposure.

In this application, exposure in each year is a binary variable equal to 1 if a worker was ever exposed to metalworking fluids of the corresponding type in that year, and 0 otherwise. The analysis therefore concerns duration of exposure rather than cumulative exposure. Probability of exposure among the actively employed was predicted in a pooled logistic model on the basis of age, decade, plant, history of time off work and prior exposure to each fluid type; results are thus 'adjusted' for those variables. Also included in the exposure model was the maximum follow-up time possible for that worker (a variable required by g-estimation). Censoring (administrative, loss to follow-up, competing risks) was handled as described in Chevrier et al. ${ }^{13}$

We stratified by race and gender, and ran separate analyses. The effect is expressed in terms of the average number of years of life that would have been saved (or lost), among the exposed cases, under an intervention banning exposure to the corresponding type of metalworking fluid without intervening on the exposures to the other fluid types.

We also used stratified g-estimation models to assess if synthetic exposure caused people to leave work differentially by race and gender.

SAS software V.9.3 (SAS Institute Inc, Cary, North Carolina, USA) was used for the g-estimation and categorical analyses, and $\mathrm{R}$ software (R Development Core Team, Vienna, Austria) was used for the spline analysis.

\section{RESULTS}

The characteristics of the total cohort and the subcohorts by race and gender are presented in table 1 . White men comprise the majority of the cohort (72\%) followed by black men (16\%), white women (9\%) and black women (3\%). There were 2246, 295, 119 and 2 IHD deaths in each subcohort, respectively. White and black men had similar years of birth and died from IHD at similar ages; however, the women were different from the men and from each other. White women were older than the men and died of IHD at older ages. Black women were strikingly younger and hired much later than the other three subcohorts. Black men had the longest duration of employment. Women had a lower mean exposure to soluble metalworking fluid than men, and black male autoworkers had a lower mean exposure to synthetic fluid, but higher exposure to soluble fluid, than their white counterparts. 
Table 1 Tabulations of study participants, demographics and exposure to metalworking fluid in a study of autoworkers; subcohorts by race and gender

\begin{tabular}{|c|c|c|c|c|c|}
\hline Characteristic & Total cohort & White men & Black men & White women & Black women \\
\hline Number of participants & 39412 & 28478 & 6137 & 3517 & 1280 \\
\hline Number of person-years & 967812 & 717707 & 148228 & 80533 & 21344 \\
\hline Number of IHD cases & 2662 & 2246 & 295 & 119 & 2 \\
\hline \multicolumn{6}{|l|}{ Demographics; median (25th, 75th) } \\
\hline Year of birth & $1931(1920,1945)$ & $1931(1920,1944)$ & 1930 (1921, 1944) & $1924(1917,1945)$ & $1947(1939,1952)$ \\
\hline Year of hire & $1955(1950,1968)$ & $1955(1950,1967)$ & $1959(1948,1968)$ & $1953(1952,1976)$ & $1973(1972,1976)$ \\
\hline Case Age (years) & $64(55,72)$ & $64(55,72)$ & $63(55,71)$ & $69(61,76)$ & $55(54,55)$ \\
\hline Duration of employment (years) & $20.1(10.3,28.6)$ & $19.8(9.0,28.9)$ & $24.7(16.8,30.1)$ & $17.3(10.1,22.1)$ & $18.7(16.3,21.6)$ \\
\hline \multicolumn{6}{|l|}{ Soluble metalworking fluid } \\
\hline Ever exposed; N(\%) & $35031(89 \%)$ & $25444(89 \%)$ & $5562(91 \%)$ & $2926(83 \%)$ & $1099(86 \%)$ \\
\hline $\mathrm{mg} / \mathrm{m}^{3}$-year ; median (25th, 75th) & $1.52(0.56,3.95)$ & $1.58(0.62,3.88)$ & $2.41(0.69,6.62)$ & $0.73(0.23,1.79)$ & $0.49(0.15,1.03)$ \\
\hline Person-years exposed; N (\%) & $359914(37 \%)$ & $271906(38 \%)$ & $59694(41 \%)$ & $20482(25 \%)$ & $7832(36 \%)$ \\
\hline \multicolumn{6}{|l|}{ Synthetic metalworking fluid } \\
\hline Ever exposed; $\mathrm{N}(\%)$ & $13804(35 \%)$ & $10805(38 \%)$ & $1206(20 \%)$ & $1379(39 \%)$ & $414(32 \%)$ \\
\hline $\mathrm{mg} / \mathrm{m}^{3}$-year; median (25th, 75th) & $0.18(0.05,0.63)$ & $0.20(0.05,0.66)$ & $0.10(0.03,0.34)$ & $0.16(0.04,0.68)$ & $0.06(0.02,0.13)$ \\
\hline Person-years exposed; $N$ (\%) & $101092(10 \%)$ & $82142(11 \%)$ & $8886(6 \%)$ & $7601(24 \%)$ & $2463(11 \%)$ \\
\hline
\end{tabular}

In the analyses of cumulative exposure, the proportional hazards analysis for white men showed no increased risk of IHD associated with either soluble or synthetic metalworking fluid. Spline models show a very slightly positive increased risk, with very wide confidence bands, among white men who were exposed to soluble or synthetic fluids (results not shown). Black men, similarly, had no increased risk associated with soluble fluid; however, risk appeared greatly elevated for black men exposed to synthetic fluid with the HR climbing to 3.29 (95\% CI 1.49 to 7.31 ) in the highest category of exposure (table 2). Spline models also show an increased risk of IHD among black men exposed to synthetic fluid. These models were restricted to plants 1 and 2 as there were no black male cases exposed to synthetic fluid in plant 3. The exposure-response pattern for IHD in black men was approximately linear with the HR climbing to 3.5 at $0.80 \mathrm{mg} / \mathrm{m}^{3}$-year and was statistically significant across the whole range of exposure (figure 1).

In the analyses of cumulative exposure for the women, there was elevated IHD risk for white women exposed to soluble fluid with the HR rising to 2.44 (95\% CI 0.96 to 6.22) in the second to last exposure category before dropping slightly (table 2). There was a suggestion of increased risk of IHD for women exposed to synthetic fluid with the HR increasing to 1.37 (95\% CI 0.82 to 2.29) in the top category of exposure. Spline models also show a positive trend for both fluid types in white women. These models were restricted to plants 2 and 3 since there were no white female cases exposed to synthetic fluid in plant 1. The risk of IHD for white women exposed to synthetic metalworking fluid rose to twofold at $2 \mathrm{mg} / \mathrm{m}^{3}$-year before falling off toward the null, however the confidence bands included the null for most of the exposure range (results not shown). The risk of IHD for white women exposed to soluble fluid rose, levelled off, and rose again to a HR of 2.25 at $8 \mathrm{mg}$ $\mathrm{m}^{3}$-year with the lower confidence band crossing back and forth across the null throughout most of the range of exposure (figure 2). Sensitivity analyses restricted to workers with known race did not change the results for white men or white women exposed to synthetic fluid, however the results were stronger for

Table 2 Association of cumulative exposure to metalworking fluid with ischaemic heart disease mortality in autoworkers by race and gender

\begin{tabular}{|c|c|c|c|c|c|c|c|c|c|c|c|c|}
\hline \multirow{2}{*}{$\begin{array}{l}\text { Cumulative } \\
\text { metalworking } \\
\text { fluid exposure } \\
\text { type and } \\
\text { amount (mg/ } \\
\mathrm{m}^{3} \text {-year) }\end{array}$} & \multicolumn{4}{|c|}{ White males } & \multicolumn{4}{|c|}{ Black males } & \multicolumn{4}{|c|}{ White females } \\
\hline & $\begin{array}{l}\text { Number } \\
\text { of cases }\end{array}$ & $\begin{array}{l}\text { Number of } \\
\text { person-years }\end{array}$ & $H^{*}$ & $(95 \% \mathrm{Cl})$ & $\begin{array}{l}\text { Number } \\
\text { of cases }\end{array}$ & $\begin{array}{l}\text { Number of } \\
\text { person-years }\end{array}$ & $H R^{*}$ & $(95 \% \mathrm{Cl})$ & $\begin{array}{l}\text { Number } \\
\text { of cases }\end{array}$ & $\begin{array}{l}\text { Number of } \\
\text { person-years }\end{array}$ & $H R^{*}$ & $(95 \% \mathrm{Cl})$ \\
\hline \multicolumn{13}{|l|}{ Soluble } \\
\hline 0 & 204 & 89559 & 1.00 & & 21 & 17953 & 1.00 & & 6 & 14693 & 1.00 & \\
\hline $0-0.76$ & 321 & 181002 & 1.01 & 0.85 to 1.21 & 33 & 34343 & 1.16 & 0.67 to 2.01 & 28 & 33175 & 1.84 & 0.76 to 4.50 \\
\hline $0.77-1.80$ & 388 & 157196 & 1.00 & 0.84 to 1.19 & 25 & 21635 & 0.96 & 0.54 to 1.73 & 29 & 16045 & 2.40 & 0.97 to 5.91 \\
\hline $1.81-3.44$ & 362 & 112165 & 0.94 & 0.78 to 1.12 & 44 & 19699 & 1.33 & 0.79 to 2.24 & 27 & 8691 & 2.44 & 0.96 to 6.22 \\
\hline$>3.44$ & 971 & 177784 & 1.01 & 0.87 to 1.18 & 172 & 54600 & 1.01 & 0.64 to 1.61 & 29 & 7929 & 1.89 & 0.74 to 4.86 \\
\hline \multicolumn{13}{|l|}{ Synthetic } \\
\hline 0 & 1449 & 485431 & 1.00 & & 275 & 127499 & 1.00 & & 64 & 53464 & 1.00 & \\
\hline $0-0.65$ & 543 & 173166 & 1.01 & 0.90 to 1.13 & 10 & 17740 & 1.38 & 0.64 to 2.97 & 30 & 19764 & 1.29 & 0.80 to 2.07 \\
\hline$>0.65$ & 254 & 59110 & 0.92 & 0.79 to 1.06 & 10 & 2991 & 3.29 & 1.49 to 7.31 & 25 & 7305 & 1.37 & 0.82 to 2.29 \\
\hline
\end{tabular}

*Adjusted for type of metalworking fluid, manufacturing plant, year and age (as time metric). 


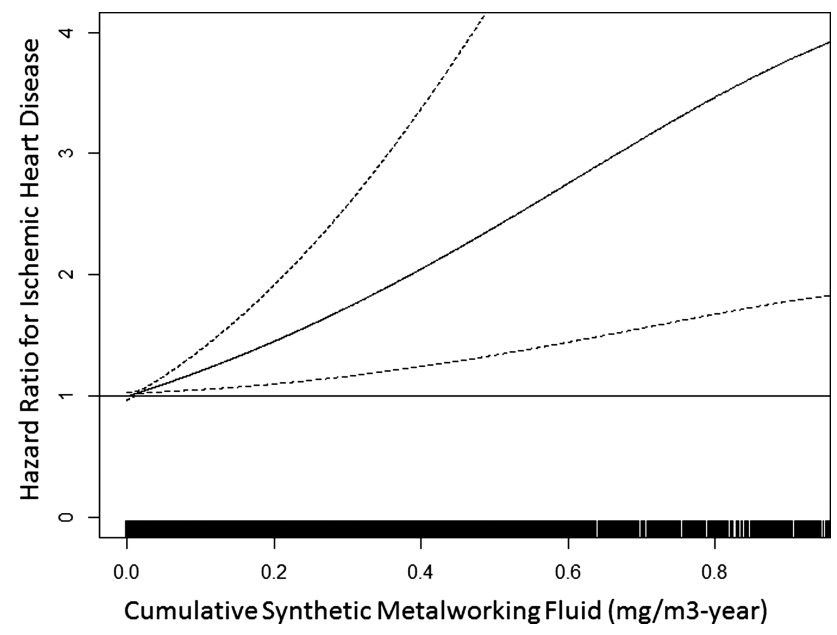

Figure 1 Association of cumulative exposure to synthetic metalworking fluid with ischaemic heart disease mortality in Black male autoworkers in plants 1 and 2 .

white women exposed to soluble fluid (results not shown). In additional sensitivity analysis, the apparent lack of effect in white men persisted when we calculated the HR for duration of exposure to soluble and synthetic fluids (results not shown).

We evaluated the risk of cardiopulmonary mortality among black women with exposure to water-based metalworking fluids modelled as continuous exposures. Based on 31 deaths from cardiopulmonary disease, the HRs for soluble and synthetic fluid were 1.17 (95\% CI 0.97 to 1.40 ) and 3.72 (95\% CI 0.94 to 14.76$)$, respectively.

In the accelerated failure time models correcting for the healthy worker survivor effect, g-estimation indicated that if cases exposed to synthetic fluid had been unexposed then 2.77 $(-12.81$ to 5.74$), 1.20(0.11$ to 2.73$)$ and $1.96(-1.43$ to 4.68$)$ years of life would have been saved on average among black men, white men and white women, respectively. If the cases had been unexposed to soluble fluid, 2.99 and 1.59 ( -0.20 to 2.99 ) years of life would have been saved among the white women and white men, respectively, whereas an average of 1.63 $(-5.26$ to 2.70$)$ years would have been lost among the black men. However, the CIs were too wide to draw meaningful

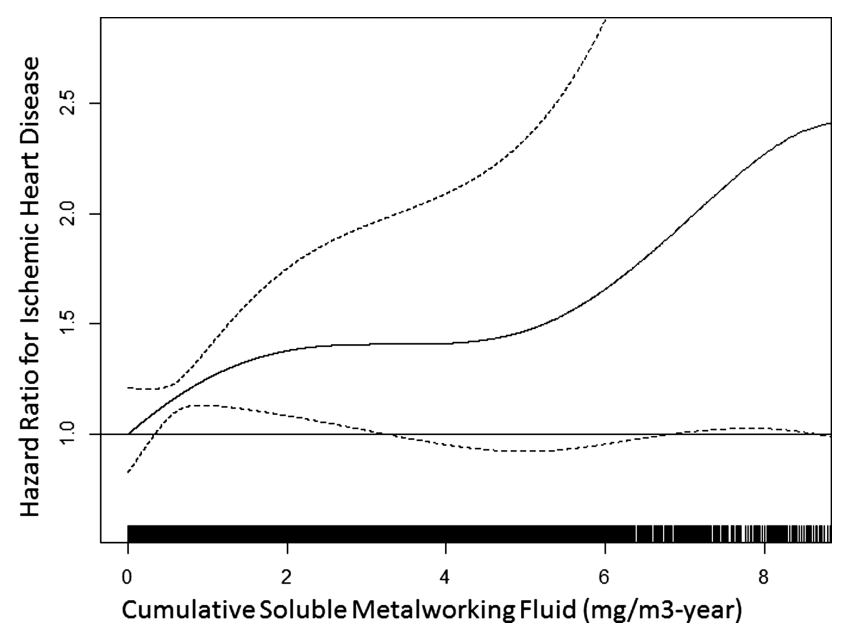

Figure 2 Association of cumulative exposure to soluble metalworking fluid with ischaemic heart disease mortality in White female autoworkers in plants 2 and 3.

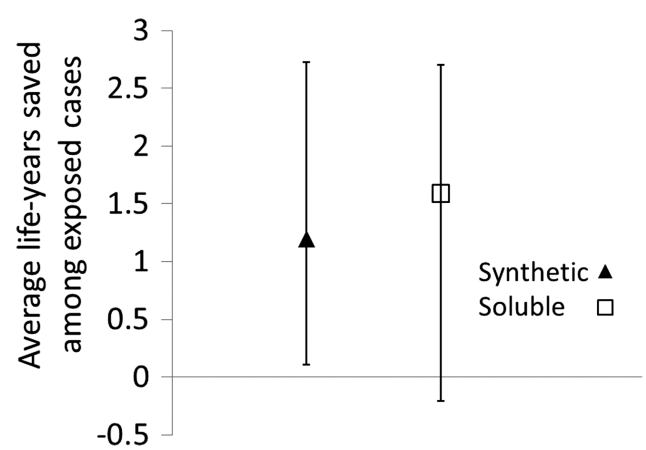

Figure 3 Average years of life saved among ever-exposed ischaemic heart disease cases, stratified by race and gender under an intervention banning either synthetic or soluble metalworking fluid.

conclusions, except among the white men (figure 3). Statistical instability precluded us from calculating CIs at all for white women exposed to soluble fluids.

G-estimation was used to assess whether exposure predicted leaving work, a critical component of the healthy worker survivor effect. Results indicated that white male, black male and white female cases exposed to synthetic fluid would have worked $1.9,0.5$ and 0 years longer, respectively, had they been unexposed.

\section{DISCUSSION}

The risk of IHD in relation to water-based metalworking fluids differed by race and gender in this cohort of autoworkers when using exposure-response models. Black men and white women had increased risk of IHD with increased exposure to at least one type of metalworking fluid, however no increased risk was observed among white men. We did, however, observe increased risk among white men after correcting for the healthy worker survivor effect using g-estimation. The healthy worker survivor effect arises when susceptible workers leave work or transfer to lower exposed jobs; an option that may be more available to white, male workers. ${ }^{14}$ Thus, results from the proportional hazards models seem to have been most dramatically attenuated by the healthy worker survivor bias for white men. All workers appear to be at increased risk of IHD with increased exposure; however, g-estimation was needed to observe the effect among white male autoworkers.

We estimated the effect of metalworking fluid on IHD in strata of autoworkers using two methods that produced somewhat different results. These methods, however, answer different questions: the standard proportional hazards model estimates the conditional effect of cumulative, quantitative exposure on the hazard of IHD on the multiplicative scale while the accelerated failure time model estimates the marginal effect of duration of exposure on survival time on the additive scale. Each method has strengths and weaknesses. The primary strength of the standard model is being able to handle quantitative exposure in a familiar way; however, the model cannot address healthy worker survivor effect. G-estimation of the accelerated failure time, on the other hand, removes the healthy worker survivor bias but sacrifices the quantitative exposure information. In addition, g-estimation appears to have power limitations in the smaller strata. We do not expect either model alone to give the definitive answer, but rather combine the strengths of each to provide a more complete assessment.

The combined evidence from both models indicates that there is an effect in all subgroups, and thus was inconclusive as to 
whether disparities exist. Effect measure modification depends on the measure of effect, so finding evidence of disparities in the proportional hazard, but not accelerated failure time, models is not necessarily in conflict. Our results are consistent with disparities in the exposure-response or with disparities only in the healthy worker survivor effect. We discuss these possibilities in light of the occupational and social literature.

\section{Gender and racial differences in work organisation and healthy worker survivor effect}

Women are more likely than men to face discrimination, harassment and lower pay for equal work in a variety of occupational settings. ${ }^{15}$ In a cohort of hourly aluminium workers, women were more likely to have lower education, less skilled jobs and be single parents. ${ }^{16}$ If the female autoworkers in this cohort have a similar demographic profile, they may have pressing financial incentive to keep their autoworker job, even if ill, and less opportunity to find employment with lower exposure. However, in the sole study of gender differences in the healthy worker effect to date, ${ }^{7}$ female synthetic vitreous fibre workers were found to have a higher mortality ratio after leaving employment than men. The authors interpreted these results as evidence of increased healthy worker survivor effect among women.

Workplace discrimination also occurs for racial minorities. Black workers are more likely to experience involuntary job $\operatorname{loss}^{17}$ and were shown to have greater perceived job insecurity in two nationally representative US samples. ${ }^{18}$ Perceived job insecurity has been linked to atherosclerosis ${ }^{19}$ on its own, and may also influence the decision to stay at work.

Given the real and perceived differences in job placement and insecurity, as well as the additional social and economic burden, the black and female autoworkers might have been less likely than white men to voluntarily opt out of the workforce for health-related reasons, which could lead to differences in the observed healthy worker survivor effect. In fact, if black and female autoworkers do not opt out of the work force for health-related reasons, then there is no time-varying confounding affected by prior exposure and the proportional hazards model may provide an unbiased estimate of IHD risk in these subgroups. We cannot test this assumption directly, as we do not have a measure of time-varying health status. However, our analysis of whether exposure to synthetic fluid causes people to leave work, another necessary piece of the healthy worker effect, indicated that white men were more likely to leave work for exposure-related reasons than either black men or white women.

\section{Gender and racial differences in heart disease}

In addition to the disparities apparent in the proportional hazards models, the point estimates using g-estimation indicate that the years of life lost for black men and white women exposed to synthetics may be greater than for white men even after correction for the healthy worker survivor effect (though the CIs reflect a lack of statistical stability in all but the white men in the g-estimation analysis).

Recent interest in gender differences in cardiovascular disease has led to a better understanding of the differences between men and women in pathophysiology, diagnosis and treatment. ${ }^{20}$ Likely due to the protective effects of oestrogen, women generally develop IHD 10 years later than men, ${ }^{21}$ and they typically have coexisting or chronic disease. Additionally, non-invasive diagnostic tests such as electrocardiogram and the treadmill stress test have lower sensitivity and specificity in women compared to men. Several observational trials have reported that women are prescribed and/or utilise recommended interventions at a lower rate than men, ${ }^{22}$ although the reasons for this discrepancy are still not understood.

Racial disparities are predominant issues in healthcare reform. Blacks are 2-3 times more likely to die from heart disease compared to whites, ${ }^{23}$ have more heart disease risk factors, ${ }^{24}$ and receive a lower quality of healthcare, even when controlling for access-related factors. ${ }^{25}$ Furthermore, research has shown that the experience of chronic discrimination can have a negative impact on cardiovascular health. ${ }^{26-28}$

Given the gender and racial disparities in heart disease survival, the exposure-response between metalworking fluid and IHD mortality may not be directly comparable between subgroups.

\section{Prior literature on occupational PM and IHD}

A recent meta-analysis of mostly white, male cohorts comparing high/any versus low/no PM exposure found a relative risk of 1.15 (CI 1.06 to 1.14 ) for IHD mortality. ${ }^{5}$ Since then, increased risk has been reported with $\mathrm{PAH}$ exposure in asphalt ${ }^{29}$ and smelter workers ${ }^{30}$ from cohorts of white men. In two recent studies of Chinese workers, cumulative exposure to cotton dust was associated with stroke, but not IHD, among female textile workers, ${ }^{31}$ and long-term silica exposure was associated with IHD among predominantly male miners. ${ }^{32}$

We recently published on the association between oil-based straight metalworking fluid and IHD in this cohort, adjusting for race and gender. ${ }^{33}$ These findings were driven by the effect in the white, male autoworkers with no adjustment for the healthy worker survivor effect. In a different publication, we demonstrated that g-estimation resulted in higher HRs for IHD in relation to straight metalworking fluid, as well as several other mortality outcomes, compared to proportional hazards models. ${ }^{13}$ However, the use of straight metalworking fluids has been phased out in most industries, thus our current focus is on the health effects of water-based fluids.

Water-based metalworking fluids contain endotoxin, biocides, nitrosamines, metals and other constitutes ${ }^{34}$ which may lead to lung and systemic inflammation. On entering the lungs, fine PM may cause systemic inflammatory response ${ }^{35-37}$ which can induce progression of atherosclerosi ${ }^{38} 39$ and activate cardiac myocytes and adipocytes. ${ }^{40}$ We had no prior that the biological pathway would differ by race or gender.

Smoking is an important risk factor for IHD and would be a confounder in this study if it were also associated with exposure. Smoking data were collected in a small cross-section of this cohort for a study of asthma. ${ }^{41}$ The cross-section cohort was restricted to men actively employed in 1985 and oversampled for blacks, unexposed workers and workers exposed to only one type of metalworking fluid. We used a multiple imputation procedure to impute missing smoking information for the black men in this study. Sensitivity analyses (not shown) using imputed smoking information did not change the result for IHD and synthetic exposure; however, we doubt the validity of extrapolating smoking information on current workers in 1985 to workers in the 1940s. Notably, exposure to water-based metalworking fluids was associated with reduced lung cancer mortality in this cohort, ${ }^{42}$ suggesting that the positive results presented here are not due to confounding by smoking. Nonetheless, the lack of information on potential confounders is a limitation, especially when considering a multifactorial disease like IHD. 
We stratified on race in this analysis and used two techniques to handle missing race data: reclassifying those with missing race as white and excluding those with missing race from the analysis. Although most of these workers were likely white, those who were black were never included in their correct stratum for this analysis. Excluding black workers with missing race status from the black stratum is a form of left truncation bias, since they would have been correctly classified as black had they stayed at work until the electronic employment record system was implemented. Left truncation bias can attenuate the observed association between exposure and disease because those who stay for longer are more heavily exposed and are less susceptible to the exposure-response association. ${ }^{43}$ Missing race status is a limitation in this analysis and may have attenuated the observed associations for black men. However, only $10 \%$ of the workers were missing information on race.

\section{CONCLUSION}

To our knowledge, this is the first time the association between occupational exposure to $\mathrm{PM}_{3.5}$ and IHD mortality has been reported by race and gender from a single cohort. Additionally, this is the first time g-estimation has been applied to understand the race and gender differences in the healthy worker survivor effect. We were able to leverage the strengths of two different analytic approaches to shed light on the health risks of metalworking fluids among autoworkers. We found that black men and white women had increased risk of IHD with increased exposure to at least one of the two types of water-based metalworking fluids, however no increased risk was observed among white men when using proportional hazard models to estimate risk. We did, however, observe increased risk among white men after correcting for the healthy worker survivor effect, which suggests that the aetiological effect of water-based metalworking may be the same in all subsets of our population. Alternatively, black and female workers may experience more IHD from waterbased metalworking fluid exposure either because of steeper exposure-response or weaker healthy worker survivor effect.

Correction notice The section head of this article has been changed since published Online First.

Contributors SC conceived the article topic and design, proportional hazard analysis, interpretation of both analytic methods and drafted most of the article. SP conducted the g-estimation analysis and contributed to the interpretation and writing, especially in regards to her analytic approach. DHR contributed to the analytic design and critically reviewed and revised the paper, especially in regards to the social disparities content. EAE is the principal investigator of the cohort study and contributed substantially to the analytic approach, analysis, interpretation and review of this article. All authors had approval of the final version and consider this honest work.

Funding This work was supported by the National Institute for Occupational Safety and Health, Centers for Disease Control (R01 OH008927).

Competing interests None.

Ethics approval University of California, Berkeley Committee for Protection of Human Subjects.

Provenance and peer review Not commissioned; externally peer reviewed.

Open Access This is an Open Access article distributed in accordance with the Creative Commons Attribution Non Commercial (CC BY-NC 3.0) license, which permits others to distribute, remix, adapt, build upon this work non-commercially, and license their derivative works on different terms, provided the original work is properly cited and the use is non-commercial. See: http://creativecommons.org/ licenses/by-nc/3.0/

\section{REFERENCES}

1 Wong MD, Shapiro MF, Boscardin WJ, et al. Contribution of major diseases to disparities in mortality. N Engl J Med 2002;347:1585-92.
2 Rosamond WD, Chambless LE, Heiss G, et al. Twenty-two-year trends in incidence of myocardial infarction, coronary heart disease mortality, and case fatality in 4 US communities, 1987-2008. Circulation 2012;125:1848-57.

3 Mosca L, Benjamin EJ, Berra K, et al. Effectiveness-based guidelines for the prevention of cardiovascular disease in women-2011 update: a guideline from the American Heart Association. Circulation 2011;123:1243-62.

4 Brook RD, Rajagopalan S, Pope CA, et al. Particulate matter air pollution and cardiovascular disease. An update to the scientific statement from the American Heart Association. Circulation 2010;121:2331-78

5 Fang SC, Cassidy A, Christiani DC. A systematic review of occupational exposure to particulate matter and cardiovascular disease. Int J Environ Res Public Health 2010:7:1773-806.

6 Robinson JC. Racial inequality and the probability of occupation-related injury or illness. Milbank Mem Fund Q Health Soc 1984;62:567-90.

7 Lea C, Hertz-Picciotto I, Andersen A, et al. Gender differences in the healthy worker effect among synthetic vitreous fiber workers. Am J Epidemiol 1999:150:1099-106.

8 Eisen EA, Bardin J, Gore R, et al. Exposure-response models based on extended follow-up of a cohort mortality study in the automobile industry. Scand I Work Env Heal 2001;27:240-9.

9 Eisen EA, Tolbert PE, Monson RR, et al. Mortality studies of machining fluid exposure in the automobile industry I: a standardized mortality ratio analysis. Am J Ind Med 1992;22:809-24.

10 Woskie SR, Smith TJ, Hallock MF, et al. Size-selective pulmonary dose indices for metal-working fluid aerosols in machining and grinding operations in the automobile manufacturing industry. Am Ind Hyg Assoc J 1994;55:20-9.

11 Hallock MF, Smith TJ, Woskie SR, et al. Estimation of historical exposures to machining fluids in the automotive industry. Am J Ind Med 1994;26:621-34

12 Robins JM, Blevins D, Ritter G, et al. G-estimation of the effect of prophylaxis therapy for pneumocystic carinii pneumonia on the survival of AIDS patients. Epidemiology 1992;3:319-36.

13 Chevrier J, Picciotto S, Eisen EA. A comparison of standard methods with g-estimation of accelerated failure-time models to address the healthy-worker survivor effect: application in a cohort of autoworkers exposed to metalworking fluids. Epidemiology 2012;23:212-19.

14 Kalleberg AL. The rise of polarized and precarious employment systems in the United States, 1970s to 2000s. New York: Russell Sage Foundation, 2011.

15 Gutek BA. Women and paid work. Psychol Women Q 2001;25:379-93.

16 Clougherty JE, Souza K, Cullen MR. Work and its role in shaping the social gradient in health. Ann N Y Acad Sci 2010;1186:102-24.

17 Park H, Sandefur GD. Racial/ethnic differences in voluntary and involuntary job mobility among young men. Soc Sci Res 2003;32:347-75.

18 Burgard SA, Brand JE, House JS. Perceived job insecurity and worker health in the United States. Soc Sci Med 2009;69:777-85.

19 Muntaner C, Nieto FJ, Cooper L, et al. Work organization and atherosclerosis: findings from the ARIC study. Am J Prev Med 1998;14:9-18.

20 Maas AHEM, van der Schouw YT, Regitz-Zagrosek V, et al. Red alert for women's heart: the urgent need for more research and knowledge on cardiovascular disease in women: proceedings of the workshop held in Brussels on gender differences in cardiovascular disease, 29 September 2010. Eur Heart J 2011:32:1362-8.

21 Papadopoulou S A, Kaski JC. Ischaemic heart disease in the ageing woman. Best Pract Res Clin Obstet Gynaecol 2013;27:689-97.

22 Ciambrone G, Kaski JC. The importance of gender differences in the diagnosis and management of cardiovascular disease. Curr Pharm Des 2011;17:1079-81.

23 Lloyd-Jones D, Adams RJ, Brown TM, et al. Executive summary: heart disease and stroke statistics - 2010 update: a report from the American Heart Association. Circulation 2010;121:948-54.

24 Hozawa A, Folsom AR, Sharrett AR, et al. Absolute and attributable risks of cardiovascular disease incidence in relation to optimal and borderline risk factors: comparison of African American with white subjects-atherosclerosis risk in communities study. Arch Intern Med 2007;167:573-9.

25 Schulman KA, Berlin JA, Harless W, et al. The effect of race and sex on physicians' recommendations for cardiac catheterization. N Engl J Med 1999;340:618-26.

26 Cuffee $\mathrm{YL}$, Hargraves JL, Allison J. Exploring the association between reported discrimination and hypertension among African Americans: a systematic review. Ethn Dis 2012;22:422-31

27 Beckie TM. A systematic review of allostatic load, health, and health disparities. Biol Res Nurs 2012;14:311-46.

28 Mays VM, Cochran SD, Barnes NW. Race, race-based discrimination, and health outcomes among African Americans. Annu Rev Psychol 2007;58:201-25.

29 Burstyn I, Kromhout H, Partanen T, et al. Polycyclic aromatic hydrocarbons and fatal ischemic heart disease. Epidemiology 2005;16:744-50.

30 Friesen MC, Demers PA, Spinelli JJ, et al. Chronic and acute effects of coal tar pitch exposure and cardiopulmonary mortality among aluminum smelter workers. Am J Epidemiol 2010;172:790-9. 
31 Gallagher LG, Ray RM, Li W, et al. Occupational exposures and mortality from cardiovascular disease among women textile workers in Shanghai, China. Am J Ind Med 2012;55:991-9.

32 Chen $W$, Liu $Y$, Wang $H$, et al. Long-term exposure to silica dust and risk of total and cause-specific mortality in Chinese workers: a cohort study. PLoS Med 2012;9: e1001206.

33 Costello S, Garcia E, Hammond SK, et al. Ischemic heart disease mortality and $\mathrm{PM}_{3.5}$ in a cohort of autoworkers. Am J Ind Med 2013;56:317-25.

34 Friesen MC, Costello S, Thurston SW, et al. Distinguishing the common components of oil- and water-based metalworking fluids for assessment of cancer incidence risk in autoworkers. Am J Ind Med 2011;460:450-60.

35 Salvi S, Blomberg A, Rudell B, et al. Acute inflammatory responses in the airways and peripheral blood after short-term exposure to diesel exhaust in healthy human volunteers. Am J Respir Crit Care Med 1999;159:702-9.

36 Ghio AJ, Kim C, Devlin RB. Concentrated ambient air particles induce mild pulmonary inflammation in healthy human volunteers. Am J Respir Crit Care Med 2000;162: 981-8.
37 Ghio AJ, Hall A, Bassett MA, et al. Exposure to concentrated ambient air particles alters hematologic indices in humans. Inhal Toxicol 2003;15:1465-78.

38 Libby P, Ridker PM, Maseri A. Inflammation and atherosclerosis. Circulation 2002;105:1135-43.

39 Suwa T, Hogg JC, Quinlan KB, et al. Particulate air pollution induces progression of atherosclerosis. J Am Coll Cardiol 2002;39:935-42.

40 Peters A. Ambient particulate matter and the risk for cardiovascular disease. Prog Cardiovasc Dis 2011;53:327-33.

41 Greaves IA, Eisen EA, Smith TJ, et al. Respiratory health of automobile workers exposed to metal-working fluid aerosols: respiratory symptoms. Am J Ind Med 1997;32:450-9.

42 Mehta AJ, Malloy EJ, Applebaum KM, et al. Reduced lung cancer mortality and exposure to synthetic fluids and biocide in the auto manufacturing industry. Scand J Work Environ Health 2010;36:499-508.

43 Applebaum KM, Malloy EJ, Eisen EA. Reducing healthy worker survivor bias by restricting date of hire in a cohort study of Vermont granite workers. Occup Environ Med 2007;64:681-7. 